\title{
On the Correlation of Lignocellulosic Filler Composition with the Performance Properties of Poly( $\varepsilon$-Caprolactone) Based Biocomposites
}

\author{
Aleksander Hejna ${ }^{1}$ (D) $\cdot$ Mohamed Sulyman² $\cdot$ Marta Przybysz ${ }^{3} \cdot$ Mohammad Reza Saeb $^{4} \cdot$ Marek Klein $^{5}$. \\ Krzysztof Formela ${ }^{3}$
}

Received: 27 April 2018 / Accepted: 20 October 2018 / Published online: 29 October 2018

(c) The Author(s) 2018

\begin{abstract}
In this work, three types of agricultural waste: olive stones (OS), date seed (DS) and wheat bran (WB) were applied as potential lignocellulosic fillers in poly( $\varepsilon$-caprolactone) (PCL) based biocomposites. Differences in composites' performance were related to the higher content of proteins, noted for WB comparing to other fillers applied, which enhanced plasticization of PCL matrix. The mechanical properties of biocomposites were significantly affected by the agricultural waste fillers. Use of WB caused an obvious, even $25 \%$ decrease of tensile strength and hardness, which could be explained on account of glass transition temperature depletion and weaker matrix-filler interfacial interactions. Such phenomenon also increased water uptake of PCL/WB composites by more than 100\%, while for PCL/OS and PCL/DS systems only for about 50\%. Thermogravimetric analysis revealed that all investigated composites can be effectively processed without thermal decomposition. Generally, the outcome of this work demonstrated that OS, DS, and WB could be applied as promising lignocellulosic fillers used in manufacturing of high-performance polymer biocomposites.
\end{abstract}

Keywords Biocomposites $\cdot$ Poly $(\varepsilon$-caprolactone $) \cdot$ Wheat bran $\cdot$ Date seed $\cdot$ Olive stone

\section{Statement of Novelty}

Submitted manuscript presents the method of utilization of two types of agricultural wastes: date seed (DS) and olive stones (OS) in manufacturing of biopolymer-based composites, which has not been described before. Presented results show that these materials can be applied as low-cost

Aleksander Hejna

ohejna12@gmail.com; aleksander.hejna@pg.gda.pl

Krzysztof Formela

kformela.ktp@gmail.com; krzysztof.formela@pg.gda.pl

Tech-Plast Aleksander Hejna, Rotmanka, Poland

2 Radiochemical Department, Tajoura Nuclear Research Center, Tripoli, Libya

3 Department of Polymer Technology, Faculty of Chemistry, Gdansk University of Technology, Gdańsk, Poland

4 Department of Resin and Additives, Institute for Color Science and Technology, Tehran, Iran

5 Institute of Fluid-Flow Machinery, Polish Academy of Sciences, Gdańsk, Poland alternative for traditionally used lignocellulosic fillers in production of wood-polymer composites. Moreover, composites filled with OS and DS show superior properties to those with other filler-wheat bran, which was already examined in literature. The effects of analyzed fillers' application can be used in the future to engineer materials of desired mechanical properties and water uptake, strongly affect the course and rate of biocomposites' degradation.

\section{Introduction}

Wood polymer composites (WPCs) are a special group of polymer-based composites, showing specific properties, such as relatively low density, enhanced stiffness and biodegradability, which properties can be designed by proper choice of lignocellulosic filler [1]. Moreover, lignocellulosic fillers incorporated into polymer matrices can reduce the materials' costs. For instance, the application of by-products resulting from the processing of various renewable raw materials, e.g. wood, crops or fruits is a promising approach in this field. 
Materials, which can be considered as a very interesting sources of low-cost lignocellulosic fillers for WPCs are olive stones (OS) and date seeds (DS). OS are a by-product generated during manufacturing of olive oil. Its global production is estimated at $\sim 3$ million tonnes annually, $80 \%$ of which is produced in EU countries (mainly: Spain, Greece and Italy) [2]. The amount of OS generated by olive oil production depends on the applied processing method [3]. Generally, OS stand for 13-23 wt $\%$ of olive mass and are considered as by-product [4]. Their industrial applications have been already investigated to some extent and comprehensively discussed by Rodriguez et al. [5]. Among them energy production, production of activated carbon, cosmetics industry, biosorbents production or animal feeding, are especially worth mentioning. OS have been also incorporated into manufacturing of WPCs, however mainly polyolefins and poly(vinyl chloride) were used as a matrices for such applications [6-8].

Date palm is a very important crop in North Africa and Middle East, cultivated for its edible fruits [9]. Global production of date fruits exceeds 7.2 million tonnes a year. The largest producer is Egypt with annual production of over 1.5 million tonnes [10]. DSs stand for $8-15 \mathrm{wt} \%$ of total date fruit mass [11]. However, they have not generally received much attention due to their lack of popularity and commercial application [12]. In their traditional origin, in Arab world, they have been used to make drinks, which could be classified as non-caffeinated coffee [13]. Several attempts have been made to use DS in polymer composites [14-17]. Alsewailem and Binkhder [18] noted that incorporation of DS into HDPE and PS matrix resulted in the reduction of mechanical properties, due to the weak compatibility between matrix and filler phase. Ghazanfari et al. [19] also analyzed the properties of HDPE/DS composites. It was found that the application of DS resulted in a decrease of melt flow index (MFI), as well as an increase of thermal conductivity of studied composites. In other work, a decrease of the PP/DS composites' crystallinity was noted with an increasing filler content [20]. Nevertheless, almost all works related to polymer/DS composites were focused on polyolefins or epoxy resins, only few reports were associated with biodegradable polymers, such as polylactide (PLA) and poly(butylene adipate-co-terephtalate) (PBAT) [21, 22].

In our previous works, we aimed to examine the application of brewers' spent grain [23-25] and wheat bran (WB) [26] in polymer composites. We established that these lignocellulosic fillers can be successfully applied as a low-cost alternative for "conventional" fillers in WPCs. Therefore, in presented research work we aimed to investigate the potential of OS, WB and DS as fillers for a development of biocomposites based on poly ( $\varepsilon$-caprolactone) (PCL). We examined the effect of filler type and content (from 10 to 50 parts by weight) on the processing (MFI), chemical structure (FTIR analysis), thermal properties (TGA), dynamic mechanical properties (DMA), static mechanical properties (tensile strength, elongation at break, hardness) and water uptake of prepared PCL-based biocomposites.

\section{Experimental}

\section{Materials}

Poly( $\varepsilon$-caprolactone) Capa ${ }^{\mathrm{TM}} \mathrm{FB} 100$ with $\mathrm{M}_{\mathrm{w}}=100,000 \mathrm{~g} /$ mol and melting point $58-60{ }^{\circ} \mathrm{C}$ was acquired from Perstorp Holding AB (Sweden). OS were obtained from oil mill at Tripoli, Libya. DSs were collected from local manufactories of date pastes and juices in Zlitan city at the coastal region of Libya. WB was acquired from Młyn Gospodarczy Sp. J. (Poland) and used in its original state. OS and DSs were collected and put into plastic bags and immediately transported to the laboratory. Then, the material was washed completely with boiling water and soap using mixing at speed of $180 \mathrm{rpm}$ for $2 \mathrm{~h}$. Washing was repeated three times to remove oil, impurities and other undesirable materials. Next, the fillers were chemically treated by $\mathrm{KOH}$ solution for $4 \mathrm{~h}$. Then, they were washed several times with distilled water and dried to constant weight. All used fillers were mechanically grinded to obtained similar size distribution of filler particles, since the size of filler has a significant influence on the incorporation of filler in polymer matrix.

\section{Biocomposites Preparation}

Biocomposites were prepared using GMF 106/2 Brabender batch mixer. Temperature of mixing chamber was $70{ }^{\circ} \mathrm{C}$ and the rotational speed of rotors was $100 \mathrm{rpm}$, in order to provide an efficient dispersion of filler, due to high shear forces acting inside the mixer. At the beginning, PCL granules were mixed for $2 \mathrm{~min}$ in order to plasticize the polymer. Then, previously grinded fillers were added to the PCL and mixed for another $5 \mathrm{~min}$ to provide proper dispersion of modifiers. Filler content in biocomposites was from 10 to $50 \mathrm{pbw}$. Then, obtained biocomposites, without cooling and grinding, were compression molded into 2-mm thick samples at $150{ }^{\circ} \mathrm{C}$ (what guaranteed an efficient flow of material) and 4.9 $\mathrm{MPa}$ for $1 \mathrm{~min}$. After that, samples were kept in other press, with non-heated plates, until cooled down to room temperature. Poly( $\varepsilon$-caprolactone), after processing in the same conditions, was used as a reference sample. Samples of composites were coded as PCL/OS ${ }_{\mathrm{X}}$ PCL/DS $\mathrm{X}_{\mathrm{X}}$ or PCL/ $\mathrm{WB}_{\mathrm{X}}$, where $\mathrm{X}$ standed for the amount of filler used in parts by weight. 


\section{Measurements}

Particle size distribution of lignocellulosic fillers was determined by sieve analysis, according to our laboratory internal standard. Approximately $100 \mathrm{~g}$ of filler was manually sieved in a constant time (30 min), using woven cloth sieves with size of $1.02,0.75,0.50,0.25$ and $0.12 \mathrm{~mm}$, respectively.

Macro- and microelements content in lignocellulosic fillers was determined by the wavelength dispersive $\mathrm{X}$-ray fluorescence spectrometry (WD-XRF) using S8 Tiger $1 \mathrm{~kW}$ spectrometer from Bruker.

Elemental analysis $(\mathrm{C}, \mathrm{H}, \mathrm{N})$ of lignocellulosic fillers was carried out using a Flash 2000 CHNSO Analyser from Thermo Scientific.

The chemical structure of fillers and biocomposites was determined using Fourier transform infrared spectroscopy (FTIR) analysis performed by Thermo Scientific IR200 Nicolet Spectrometer with a diamond crystal ATR attachment. Measurements were performed in a $1 \mathrm{~cm}^{-1}$ resolution in the range from 4000 to $400 \mathrm{~cm}^{-1}$.

MFI of biocomposites was investigated using Zwick mFlow plastometer according to ISO 1133 at $200{ }^{\circ} \mathrm{C}$, with load of $5 \mathrm{~kg}$.

The tensile strength and elongation at break were estimated in accordance with ASTM D638. Tensile tests were performed on the Zwick Z020 apparatus with elongation head and extensometers at a constant speed of $50 \mathrm{~mm} / \mathrm{min}$. For the calculation of tensile modulus, the speed of $1 \mathrm{~mm} /$ min was applied. Five dumbbell samples, type IV according to ASTM D638 standard, were used for each specimen. Shore hardness type D was estimated using Zwick 3131 durometer in accordance with ISO 868.

Dynamic mechanical analysis was performed using DMA Q800 TA Instruments apparatus. Samples cut to the dimensions of $40 \times 10 \times 2 \mathrm{~mm}$ were loaded with a variable sinusoidal deformation force in the single cantilever bending mode at the frequency of $1 \mathrm{~Hz}$ under the temperature rising rate of $4{ }^{\circ} \mathrm{C} / \mathrm{min}$ within the temperature range between -100 and $100{ }^{\circ} \mathrm{C}$.

The results of static and dynamic mechanical analyses were used to calculate the brittleness of investigated composites, in accordance with the following formula presented by Brostow et al. [27] (Eq. 1):

$\mathrm{B}=\frac{1}{\varepsilon_{\mathrm{b}} \times E^{\prime}}$

where $B$ is the brittleness, $10^{10} \% \cdot \mathrm{Pa} ; \varepsilon_{b}$ the elongation at break, \%; $E^{\prime}$ is the storage modulus at $25^{\circ} \mathrm{C}, \mathrm{MPa}$.

Moreover, for better understanding of interactions between matrix and filler, the volume fraction of polymer chains immobilized by filler particles $\left(\mathrm{C}_{\mathrm{v}}\right)$, as well as the adhesion factor (A) determining the strength of interfacial interactions, were calculated from the results of dynamic mechanical analysis. Detailed procedures and mathematical formulas used for these calculations were presented in our previous works $[25,26]$.

Thermogravimetric analysis (TGA) was performed on a Netzsch TG 209 apparatus using 5-mg samples in the temperature range $25-600{ }^{\circ} \mathrm{C}$ and under nitrogen atmosphere, at a heating rate of $20^{\circ} \mathrm{C} / \mathrm{min}$.

The water uptake and the degradation of the materials were studied over a period of 2 weeks. Biocomposites $(0.2 \mathrm{~g}$ samples) were conditioned in room temperature and then put into distilled water in order to determine their degradation behavior. Samples were taken out and weighted after 48 , $120,144,168,312$ and $336 \mathrm{~h}$. Water uptake was determined according to the following Formula (2):

Water uptake $=\frac{\mathrm{m}_{\mathrm{t}}-\mathrm{m}_{0}}{\mathrm{~m}_{0}} \times 100 \%$

where $m_{t}$ is the mass of the sample after immersion, $\mathrm{g} ; m_{0}$ is the initial mass of sample, $\mathrm{g}$.

\section{Results and Discussion}

\section{Characteristics of Waste Lignocellulosic Fillers}

Particle size distribution of applied lignocellulosic fillers is presented in the Fig. 1. OS particles were characterized by the smallest dimensions, with $\sim 40 \mathrm{wt} \%$ of particles below $0.12 \mathrm{~mm}$. For DS filler, more than $80 \mathrm{wt} \%$ of particles were smaller than $0.50 \mathrm{~mm}$, while for WB it was over $83 \mathrm{wt} \%$. Nevertheless, only $\sim 31.5 \mathrm{wt} \%$ of WB particles was characterized by a size lower than $0.26 \mathrm{~mm}$, while for DS it was almost $61 \mathrm{wt} \%$. Such phenomenon was related to the

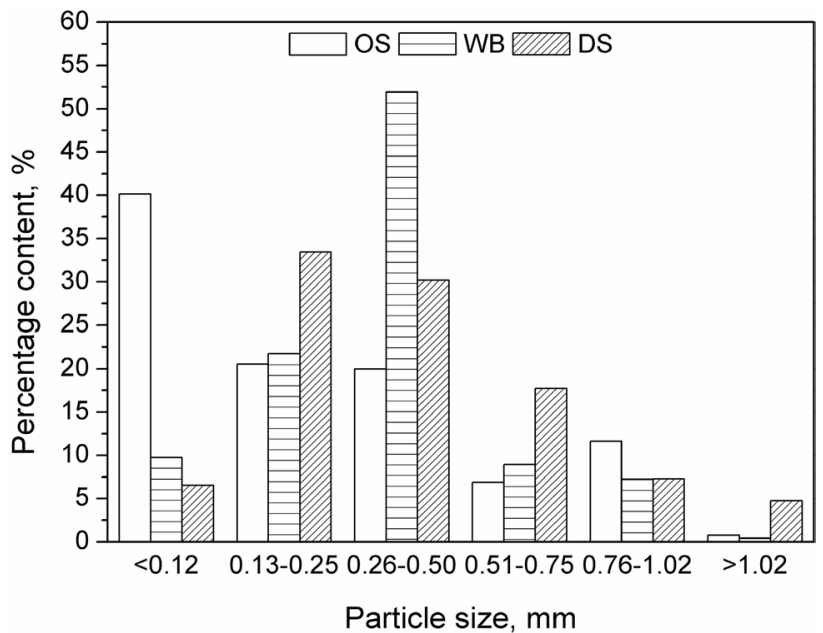

Fig. 1 Particle size distribution of analyzed lignocellulosic fillers 


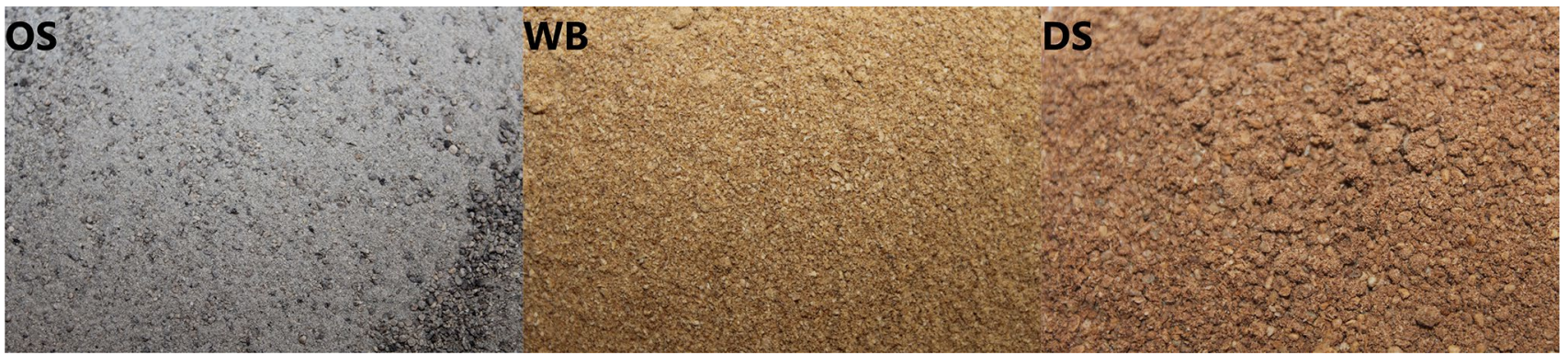

Fig. 2 Macroscopic appearance of used lignocellulosic fillers

Table 1 Elemental composition of applied lignocellulosic fillers

\begin{tabular}{|c|c|c|c|c|c|}
\hline Item & Method & Unit & OS & WB & DS \\
\hline C & Elemental analysis & $\mathrm{wt} \%$ & 46.95 & 44.92 & 44.82 \\
\hline $\mathrm{H}$ & & & 5.49 & 6.26 & 5.94 \\
\hline $\mathrm{N}$ & & & 0.26 & 2.48 & 0.82 \\
\hline $\mathrm{Ca}$ & WD-XRF & $\mathrm{wt} \%$ & 0.20 & 0.08 & 0.10 \\
\hline K & & & 0.11 & 1.26 & 0.27 \\
\hline $\mathrm{Fe}$ & & & 0.11 & 0.01 & 0.04 \\
\hline $\mathrm{Mg}$ & & & 0.03 & 0.22 & 0.07 \\
\hline S & & & 0.02 & 0.14 & 0.08 \\
\hline $\mathrm{P}$ & & & 0.02 & 0.62 & 0.07 \\
\hline $\mathrm{Cl}$ & & & 0.01 & 0.07 & 0.06 \\
\hline $\mathrm{Si}$ & & & - & - & 0.09 \\
\hline
\end{tabular}

shape of WB particles, which can be seen in the Fig. 2. The size and shape of filler particles has a great impact on their dispersion in the polymer matrix, hence on the properties of a composite material. Differences in size of applied filler particles resulted in variation in composites' porosity, which also affected the mechanical performance of materials.

Some differences in the composition of analyzed fillers, presented in Table 1, were observed. The highest carbon content was noted for OS, which can be associated with the highest amount of lignin contained in this filler (see Table 2). In comparison to cellulose, lignin contains more carbon in its structure- $61.7 \%$, versus $44.4 \%$ (determined by elemental analysis) $[28,29]$. The highest nitrogen content was observed for WB, which is related to the high content of proteins, mainly gluten [30], comparing to OS and DS filler. Moreover, analysis of applied lignocellulosic fillers with WD-XRF revealed higher content of potassium, phosphorous, magnesium and other elements in WB comparing to other fillers. Higher content of macro- and micro-elements in lignocellulose filler could support further biodegradation of studied composites, therefore, in future studies, their impact on efficiency of this process should be evaluated. Generally, presented results of OS and DSs composition analysis correspond with literature data [31, 32].
Table 2 Chemical composition of used waste lignocellulosic fillers

\begin{tabular}{llcl}
\hline Component & $\mathrm{OS}^{\mathrm{a}, \mathrm{b}}$ & $\mathrm{WB}^{\mathrm{c}, \mathrm{d}}$ & $\mathrm{DS}^{\mathrm{e}, \mathrm{f}}$ \\
\hline Cellulose & 31.9 & 21.4 & 23.9 \\
Hemicellulose & 21.9 & 26.2 & 26.8 \\
Lignin & 26.5 & 4.6 & 21.6 \\
Starch & - & 8.6 & - \\
Proteins & 2.8 & 14.4 & 6.0 \\
Lipids & 4.1 & 5.5 & 10.3 \\
Ash & 1.1 & 8.1 & 1.0 \\
\hline
\end{tabular}

${ }^{\text {a According to [5] }}$

${ }^{\mathrm{b}}$ According to [33]

${ }^{\mathrm{c}}$ According to [34]

${ }^{\mathrm{d}}$ According to [35]

${ }^{\mathrm{e}}$ According to [36]

${ }^{\mathrm{f}}$ According to [10]

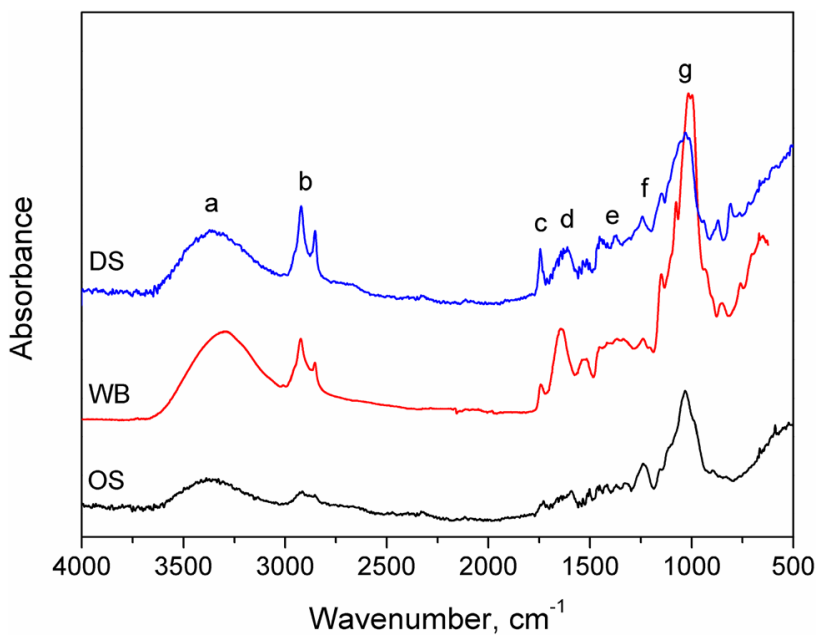

Fig. 3 FTIR spectra of waste lignocellulosic fillers

In the Fig. 3, the FTIR spectra of applied lignocellulosic fillers are presented. All analyzed fillers contained hydroxyl groups, present in polysaccharides (cellulose, hemicellulose), which was expressed by the presence of 
characteristic signal (a) in the range of $3300-3350 \mathrm{~cm}^{-1}$, responsible for their stretching vibrations. Peaks (b) in the range of $2840-2940 \mathrm{~cm}^{-1}$ were related to the symmetric and asymmetric stretching vibrations of $\mathrm{C}-\mathrm{H}$ bonds in $\mathrm{CH}_{2}$ and $\mathrm{CH}_{3}$ groups present in structure of applied fillers, more precisely in the hydrocarbon chains of polysaccharides [37]. Absorption bands present around 1740 and $1640 \mathrm{~cm}^{-1}$ (signals $\mathrm{c}$ and $\mathrm{d}$ ), were attributed to the stretching vibrations of unconjugated $\mathrm{C}=\mathrm{O}$ and $\mathrm{C}=\mathrm{C}$ bonds in polysaccharides [38]. Group of peaks (e) in the range of $1370-1460 \mathrm{~cm}^{-1}$ is related with $\mathrm{CH}_{2}$ and $\mathrm{HOC}$ in-plane bending vibrations, characteristic for carbohydrates, e.g. lignin [39, 40], while signal (f) at $1235 \mathrm{~cm}^{-1}$ is associated with the stretching of $\mathrm{C}-\mathrm{O}$ and $\mathrm{C}=\mathrm{O}$ bonds [41]. The most intensive signal $(\mathrm{g})$ was observed around $1010-1030 \mathrm{~cm}^{-1}$, which is typical for FTIR analysis of lignocellulosic fillers [42] and can be associated with the stretching vibrations of $\mathrm{C}-\mathrm{O}$ bonds [43].

\section{FTIR Analysis of Biocomposites}

In the Fig. 4 the FTIR spectra of pure PCL and biocomposites containing $50 \mathrm{pbw}$ of applied cellulosic fillers are shown. Signals (a) observed in the range of 2860-2940 $\mathrm{cm}^{-1}$ were attributed to the symmetric and asymmetric stretching vibrations of $\mathrm{C}-\mathrm{H}$ bonds in $\mathrm{CH}_{2}$ and $\mathrm{CH}_{3}$ groups present in the structure of PCL matrix. Peak (b) at $1724 \mathrm{~cm}^{-1}$ can be ascribed to the stretching vibrations of carbonyl bonds [44]. Multiple absorption bands (c) observed at $1360-1480 \mathrm{~cm}^{-1}$ were related to the deformation vibrations of C-H bonds. Signal (d) at $1294 \mathrm{~cm}^{-1}$ was associated with the stretching vibrations of $\mathrm{C}-\mathrm{O}$ and $\mathrm{C}-\mathrm{C}$ bonds in the crystalline phase of poly( $\varepsilon$-caprolactone). Slight decrease of this signal's intensity with the incorporation of lignocellulosic fillers may suggest a disturbance of crystalline structure of PCL matrix due to the presence

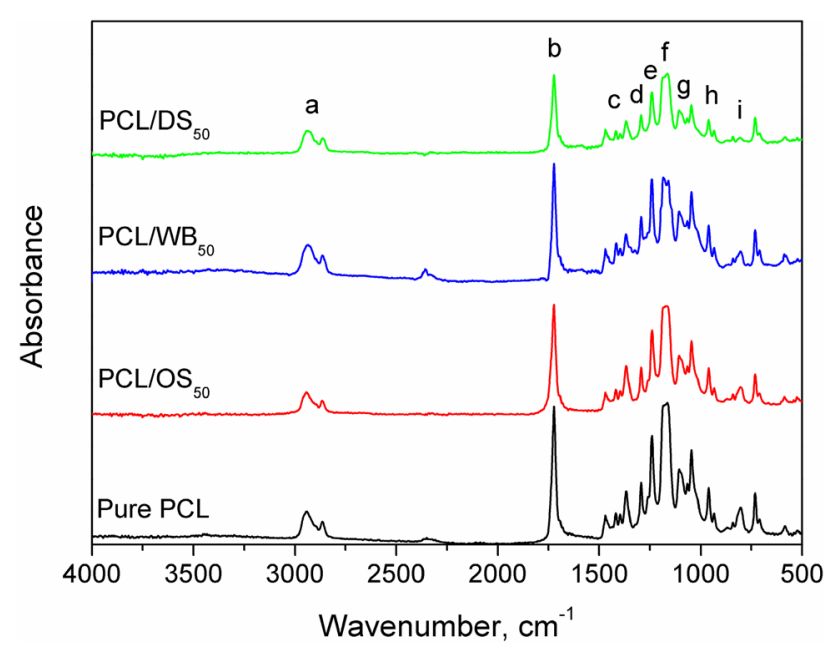

Fig. 4 FTIR spectra of pure PCL and PCL-based biocomposites of solid particles [45]. Peak (e) at $1240 \mathrm{~cm}^{-1}$ was attributed to the asymmetric stretching of COC groups. Multiplet band (f) at $1160-1190 \mathrm{~cm}^{-1}$ shows complex structure and is associated with the symmetric COC stretching, as well as stretching vibrations of $\mathrm{C}-\mathrm{O}$ and $\mathrm{C}-\mathrm{C}$ bonds in the amorphous phase of poly ( $\varepsilon$-caprolactone) [46]. Signals $(\mathrm{g})$ in the range of $1044-1106 \mathrm{~cm}^{-1}$ were attributed to the stretching of $\mathrm{C}-\mathrm{O}$ bonds. Peaks (h and i) observed from 730 to $955 \mathrm{~cm}^{-1}$ were related to the skeletal vibrations of $\mathrm{C}-\mathrm{C}$ bonds in poly ( $\varepsilon$-caprolactone) chains. It can be seen that, from the qualitative point of view, hardly any difference can be observed between analyzed materials. Moreover, negligible differences between spectra for pure poly( $\varepsilon$-caprolactone) and biocomposites indicating physical interactions at the interphase between matrix and filler.

\section{Melt Flow Index of Biocomposites}

The effects of lignocellulosic filler type and content on the MFI of studied composites were measured and plotted in Fig. 5. Both factors have noticeable influence on the flowability of biocomposites, which is obviously related to the incorporation of solid particles into poly( $\varepsilon$-caprolactone), disturbing flow of polymer matrix [47]. It can be seen that the level of MFI decrease is related to the particle size distribution of applied fillers. The most significant decrease was observed for PCL/OS composites, which is related to the smallest size of OS particles comparing to other studied fillers. In this case, physical interactions between poly( $\varepsilon$-caprolactone) matrix and filler particles were stronger, due to the larger specific surface area of applied cellulosic filler, therefore the highest melt viscosity was observed [22, 48].

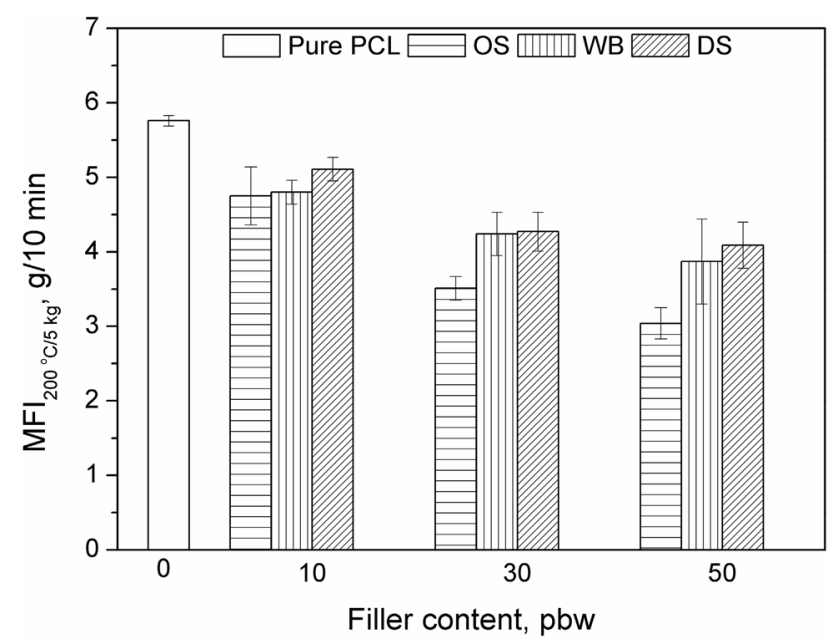

Fig. 5 MFI of biocomposites as a function of waste lignocellulosic filler type and content 


\section{Morphology of Biocomposites}

In the Fig. 6 the SEM microscopic images of investigated composites are presented. Prior to analysis, samples were cooled in liquid nitrogen in order to obtain brittle fracture area in images. It can be seen that the noticeably biggest filler particles are observed for PCL/WB composites, which confirms the results of sieve analysis. Moreover, for this group of materials the lowest compatibility can be observed, due to high porosity and lack of strong interfacial interactions, which can be also associated with the particle size of fillers [26]. Differences in morphology can be also related to the chemical composition of applied fillers, e.g. higher content of proteins and lipids, for WB and DS respectively, which can act as plasticizers [49].

\section{Static Mechanical Properties of Biocomposites}

In the Figs. 7 and 8 the impact of filler type and content on the tensile strength and elongation at break of investigated
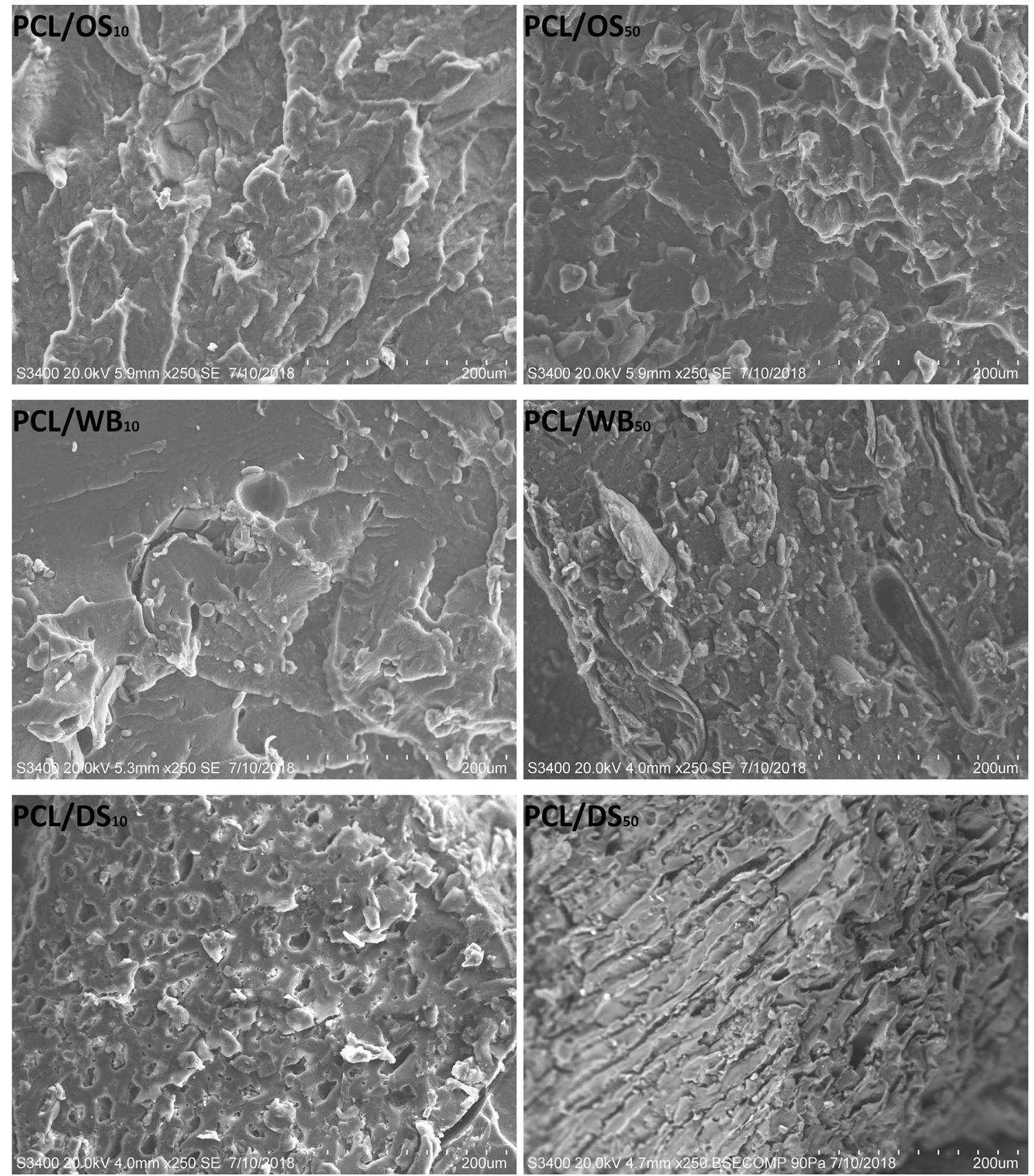

Fig. 6 SEM images of prepared biocomposites 


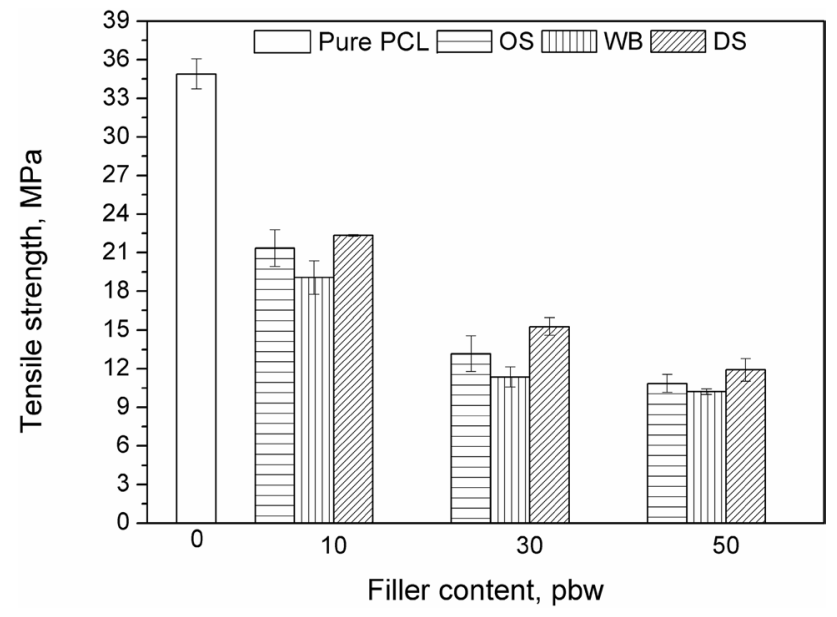

Fig. 7 Impact of type and content of lignocellulosic filler on tensile strength of biocomposites

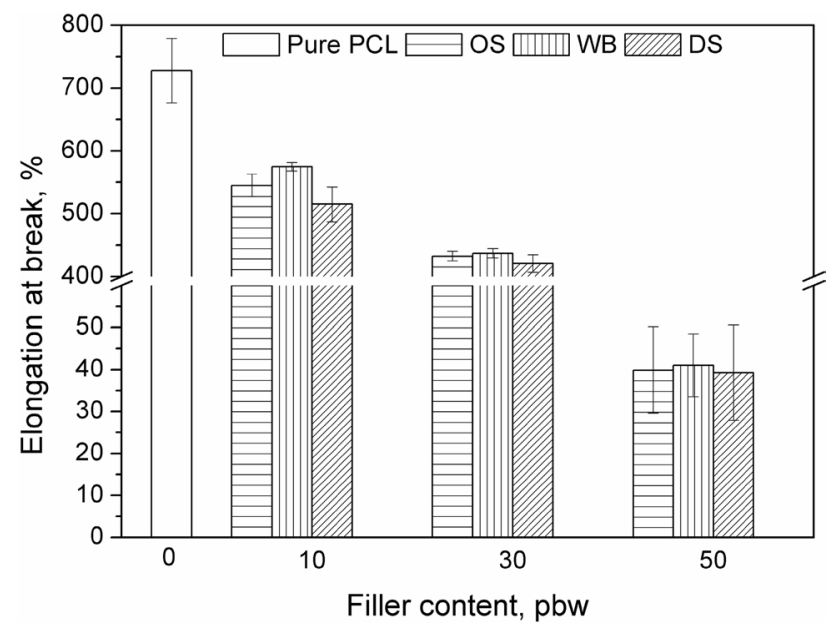

Fig. 8 Elongation at break of biocomposites as a function of lignocellulosic filler type and content

biocomposites, is shown. As could be expected, noticeable drop of these parameters was observed. It was related to the high tensile properties of poly( $\varepsilon$-caprolactone) matrix and insufficient interfacial interactions between matrix and filler phase, which was also observed in our previous work [25]. Mittal et al. [22] have made similar observations in case of PBAT/DS and PLA/DS biocomposites. They attributed the decrease of tensile strength with poor polymer-filler interactions and with too big particle size of filler, which led to the stress concentration.

Generally, in case of lower loadings, some differences between particular fillers were observed. Incorporation of WB resulted in higher decrease of tensile strength comparing to OS and DS. It can be associated with lower content of polysaccharides, such as cellulose, hemicellulose, lignin or starch, which enhances interfacial interactions with matrix, due to the high number of polar groups, e.g. hydroxyl groups [50]. Moreover, WB has higher content of proteins, which could act as plasticizers of PCL matrix [49]. This also explains the highest elongation at break for PCL/WB composites.

For the highest loadings, tensile properties were hardly dependent on filler type. In that case, the deterioration of mechanical performance was rather related to the disturbance of matrix integrity and limitation of PCL chains mobility [51].

In the Fig. 9 elastic modulus of investigated composites, determined during tensile tests are presented. As could be expected, incorporation of lignocellulosic fillers resulted in the stiffening of the material, expressed by the increase of modulus. Such phenomenon was associated with the PCL chains' mobility limited by filler particles and potential interactions between carbonyl group of PCL and polar groups present on the surface of applied fillers [7, 51]. Presented results fully confirm previous work related to polymer biocomposites containing DS filler [22].

The hardness values of biocomposites are shown in the Fig. 10. As expected, incorporation of analyzed fillers into poly( $\varepsilon$-caprolactone) matrix resulted in the increase of hardness, which confirms the results of previous works [20, 25]. The most significant rise of hardness was observed for PCL/ OS composites, from 50.2 for pure PCL to 52.8, 54.7 and $56.7^{\circ} \mathrm{Sh} \mathrm{D}$, respectively, for 10,30 and $50 \mathrm{pbw}$ of filler. This confirms enhanced physical interactions between matrix and filler phases, due to a larger specific surface area (the smallest particle size) of OS among used lignocellulosic fillers. The lowest values of hardness were observed for materials containing WB, 5\% lower than for PCL/OS composites,

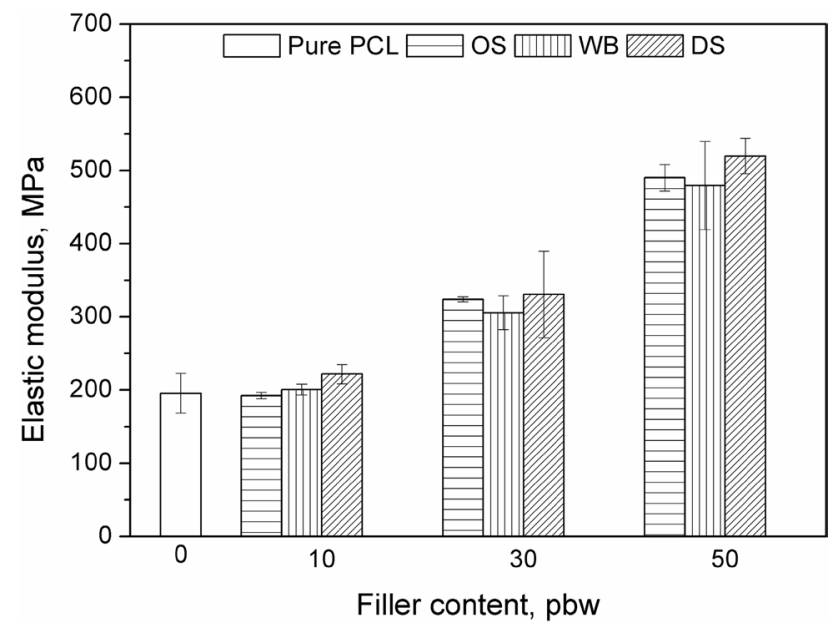

Fig. 9 Influence of content and type of lignocellulosic filler on the elastic modulus of biocomposites 


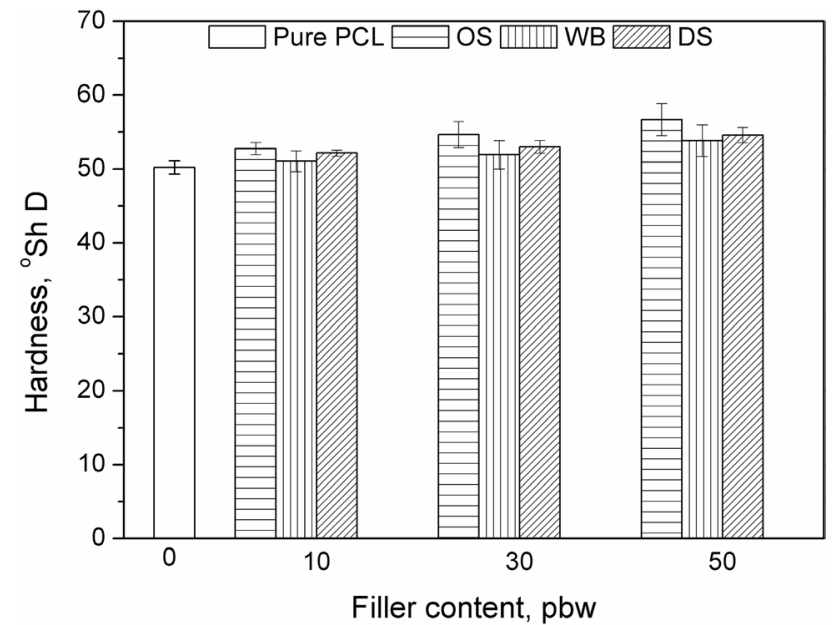

Fig. 10 Hardness of biocomposites as a function of lignocellulosic filler type and content

which is related to the presence of proteins, acting as plasticizers of poly( $\varepsilon$-caprolactone) matrix.

\section{Dynamic Mechanical Properties of Biocomposites}

In the Figs. 11 and 12 and in Table 3 the the results of dynamic mechanical analysis of prepared composites are presented. In the Fig. 11 the plots of composites' storage modulus $\left(E^{\prime}\right)$ as a function of temperature are shown. Presented plots confirm the results obtained during tensile tests, which indicated enhancement of materials' modulus and increase of hardness by addition of lignocellulose fillers. The strongest effect of stiffening was observed for PCL/DS composites, which is also in line with the results of static mechanical tests. For all samples, two phase transitions can be observed, which is related to the rapid drop of modulus. First one, the glass transition, occurs in the range of -60 to $-30{ }^{\circ} \mathrm{C}$, while the second one, noted around $70{ }^{\circ} \mathrm{C}$ is associated with melting of PCL matrix. In Table 3 the glass transition temperatures $\left(\mathrm{T}_{\mathrm{g}}\right)$ values determined as the maximum value of the loss tangent $(\tan \delta)$ curve versus temperature, are presented. It can be seen that composites containing lignocellulosic fillers showed noticeably higher values of $\mathrm{T}_{\mathrm{g}}$ (almost $6{ }^{\circ} \mathrm{C}$ difference for PCL/OS 50 sample), comparing to pure poly( $\varepsilon$-caprolactone). According to Mousa et al. [7], who also investigated incorporation of olive-based fillers into polymer matrix, it was due to the addition of rigid and stiff particles, which are restricting chain mobility, e.g. due to polar-polar interactions, as well, as hydrogen bonding between polar groups present on the surface of fillers and poly ( $\varepsilon$-caprolactone). Some differences in $\mathrm{T}_{\mathrm{g}}$ between composites with various fillers were observed. The lowest values of glass transition temperature were noted for PCL/WB
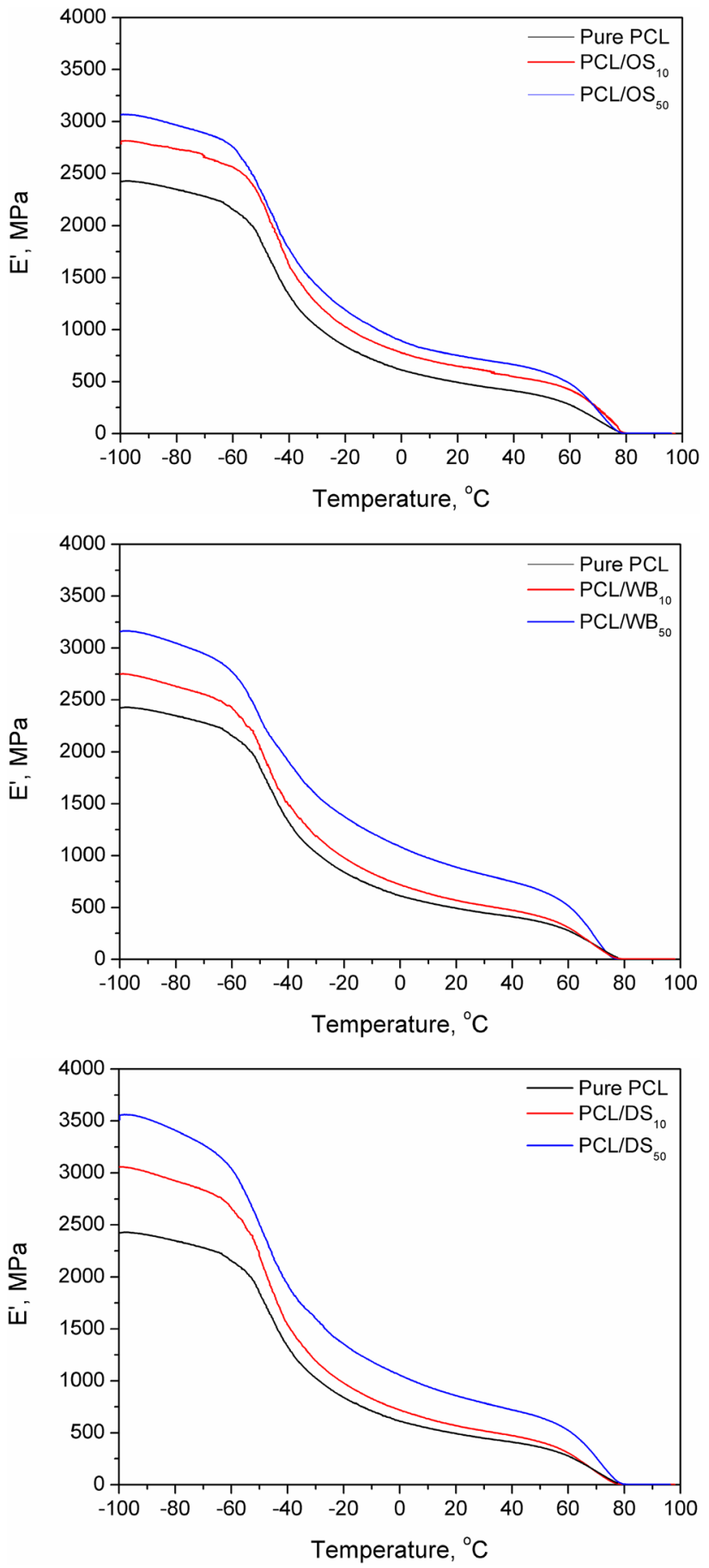

Fig. 11 Plots of $E^{\prime}$ as a function of temperature for prepared biocomposites

materials, which is related to the presence of amino acids, which enhance PCL's ability to flow under stress [52].

Moreover, in the Fig. 12 it can be seen that incorporation of waste lignocellulosic fillers not only affected the temperature position of $\tan \delta$ peak, but also its magnitude. Similar 


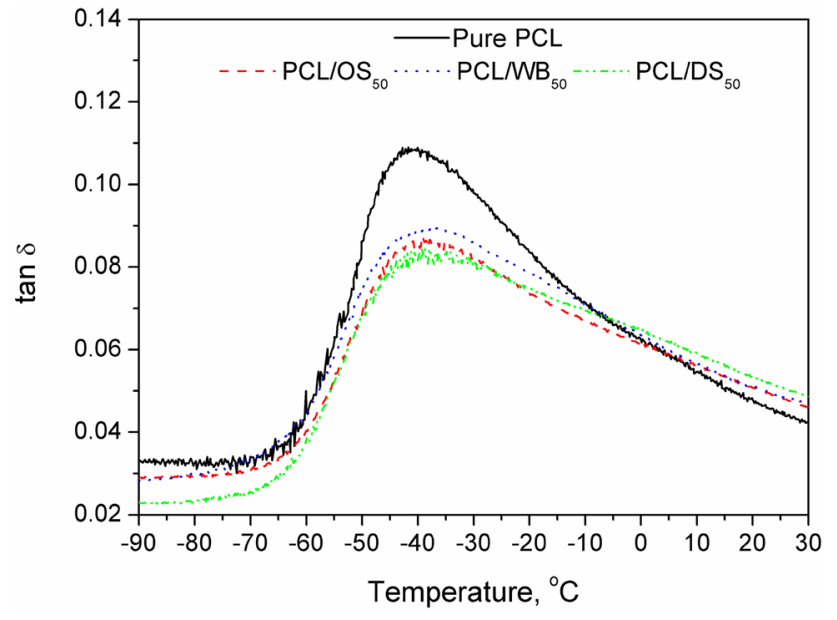

Fig. 12 Plot of $\tan \delta$ of biocomposites as a function of temperature

observations, related to the lowering of $\tan \delta$ peak, were observed by other researchers $[53,54]$.

As mentioned before, we applied methodology described in our previous works $[25,26]$ for interpretation of DMA results. We used the magnitude of $\tan \delta$ peak to calculate the constrained chains volume $\left(\mathrm{C}_{\mathrm{v}}\right)$. Results of these calculations are presented in Table 3. $\mathrm{C}_{\mathrm{v}}$ parameter is associated with the limiting of polymer chains' mobility by incorporation of solid filler particles. Such limitation occurs through polar-polar interactions and hydrogen bonding between matrix and filler phases. Lowering of $\tan \delta$ peak, as well, as its broadening, indicates reduction in the amount of mobile polymer chains.

For all composites, volume of constrained chains is increasing with the addition of filler, which confirms the stiffening of the material. Such phenomenon is associated with an increase of interfacial area and enhancement of matrix-filler interactions, due to the presence of various polar groups on the surface of applied lignocellulosic fillers. Moreover, $\mathrm{C}_{\mathrm{v}}$ value is related to the particle size distribution of used fillers. For lower particle size, the specific surface area is higher, therefore interfacial interactions between matrix and filler are enhanced. The lowest values of $\mathrm{C}_{\mathrm{v}}$ were observed for PCL/WB composites, which could be related to the highest particle size of WB filler and the highest content of proteins. Plasticizing PCL matrix by proteins might reduce stiffness of biocomposites.

We also used DMA results, more precisely values of tan $\delta$ in the temperature range of $15-35{ }^{\circ} \mathrm{C}$, to calculate the adhesion factor (A) describing the strength of interfacial interactions. Results of calculations are presented in Table 3. During calculations we assumed that due to the relatively high rigidity, $\tan \delta$ of filler can be neglected. Moreover, in case of composites characterized with very strong interfacial interactions between matrix and filler, the mobility of polymer chains in the vicinity of filler surface is significantly reduced, simultaneously reducing $\tan \delta$ of interphase. As a result, for high degree of matrix-filler interactions, value of adhesion factor is low. Calculated A values are in line with the presented values of $\mathrm{Cv}$, which suggest matrix-filler adhesion for PCL/OS and PCL/DS composites is higher than for PCL/WB samples. As a result of stronger interactions at the interphase, mechanical properties of these materials were superior to those containing WB. Stronger interphase enabled better transfer of stress inside the material, which led to higher tensile strength, stiffness or hardness. In case of composites containing $10 \mathrm{pbw}$ of fillers, negative values of adhesion factor can be observed. Such phenomenon can be associated to the simplification of proposed model and A factor calculations, when filler anisotropy and development of the interphase region were neglected, which can have impact on the matrix mobility around filler particles [55].

In Table 3 there are also presented values of materials' brittleness calculated using the results of elongation at break and storage modulus. Brittleness can be opposed to toughness, which is determined as an integrated stress-strain curve, so higher elongation at break is related to higher toughness. Storage modulus is responsible for high ability to withstand repetitive fatigue. Therefore, materials characterized with high $\varepsilon_{\mathrm{b}}$ and high $\mathrm{E}^{\prime}$ are considered as materials with low brittleness [56]. It can be seen that $B$ of composites is increasing with the share of lignocellulosic filler. Such phenomenon is associated with the weakening of interfacial interactions and drastic decrease of elongation at break. Therefore, despite the stiffening of the material, its toughness is reduced. The lowest brittleness was noted for PCL/ WB composites, which confirms the plasticization of PCL matrix due to the presence of proteins in WB.
Table 3 Results of dynamic mechanical analysis carried out for prepared biocomposites

\begin{tabular}{llcccccc}
\hline Properties & \multicolumn{7}{l}{ Sample symbol } \\
\cline { 2 - 7 } & PCL & PCL/OS & & & & \\
& PCL/OS $_{50}$ & PCL/WB $_{10}$ & PCL/WB & & PCL/DS $_{10}$ & PCL/DS $_{50}$ \\
\hline $\mathrm{T}_{\mathrm{g}},{ }^{\circ} \mathrm{C}$ & -41.7 & -37.3 & -36.0 & -40.2 & -39.1 & -38.8 & -37.9 \\
$\mathrm{C}_{\mathrm{v}}$ & 0 & 0.073 & 0.164 & 0.068 & 0.138 & 0.105 & 0.177 \\
$\mathrm{~A}$ & - & -0.025 & 0.100 & -0.019 & 0.139 & -0.069 & 0.078 \\
$\mathrm{~B}, 10^{10} \% \cdot \mathrm{Pa}$ & 0.026 & 0.029 & 0.344 & 0.025 & 0.287 & 0.029 & 0.311 \\
\hline
\end{tabular}




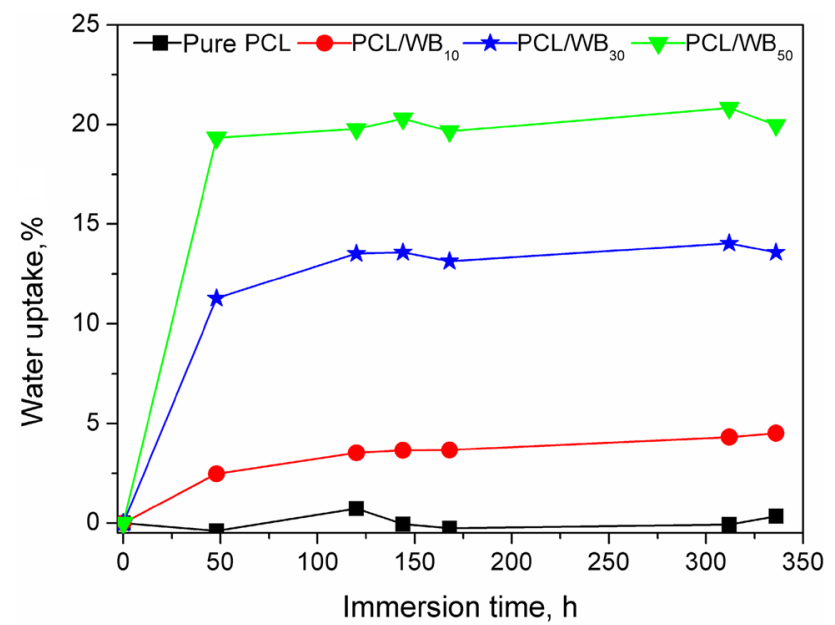

Fig. 13 Water uptake of PCL/WB biocomposites as a function of immersion time

\section{Water Uptake of Biocomposites}

In the Fig. 13 the plot of water uptake of PCL/WB composites as a function of immersion time is presented. It can be seen that with the increasing content of filler in composite its water absorption also increases, which was observed for all applied fillers, confirming results of other research [7]. Such phenomenon may be related to the increased porosity, related to the incorporation of solid particles into polymer matrix, but mainly to the fact that all fillers consist mainly of cellulose, hemicellulose, lignin and other polysaccharides (see Table 2). These components show relatively high values of water binding capacity and swelling capacity, which is due to the hydrogen bonding between polar groups present in their structure and water molecules [57-59]. Increased water uptake, hence the biodegradation ability, can be considered as a very positive feature from the potential application point of view.

In case of composite materials, water uptake is strictly related to their porosity. Incorporation of natural fillers into polymer matrix is often related to the increase of porosity, caused by inclusion during processing, insufficient wettability of fillers and poor interfacial interactions [60]. It is also the reason of the increasing ability of biocomposites to absorb water, comparing to neat polymers. Similar effect was observed in case of investigated materials. In the Fig. 14 the influence of filler type on the water uptake of prepared biocomposites is shown. The highest ability to absorb water was observed for PCL/WB composites, which is related to the porosity of material, observed on SEM images, as well as to the chemical structure of material, especially to the presence of starch in WB, which show high water uptake [61]. Moreover, also proteins show relatively high water absorption, which resulted in the

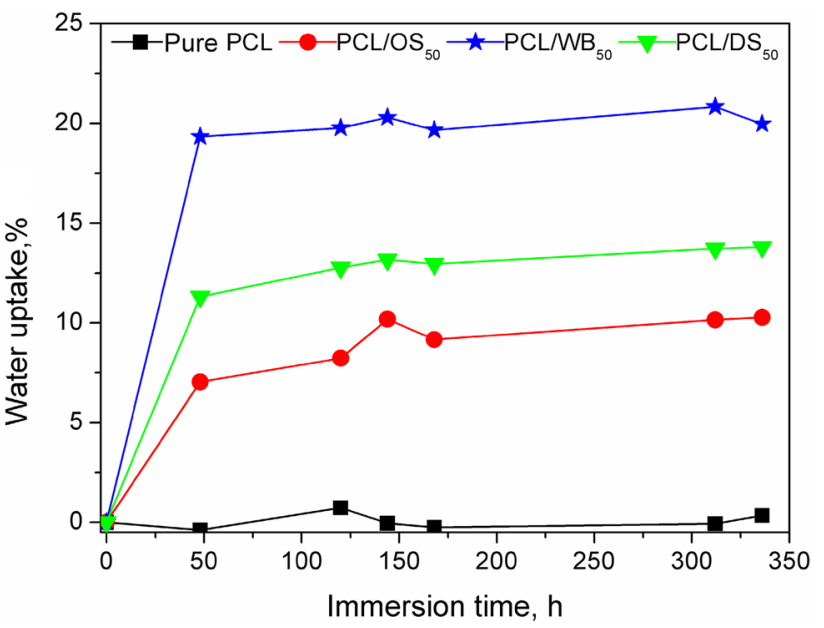

Fig. 14 Water uptake of biocomposites as a function of filler type an immersion time

higher water uptake of PCL/DS and PCL/WB comparing to PCL/OS composites (see Table 2) [62].

\section{Thermogravimetric Analysis of Biocomposites}

The results of the TGA of PCL biocomposites are presented in Table 4. Data indicate a significant deterioration of the thermal stability with the addition of applied fillers, which is associated with their relatively poor thermal stability. The highest stability was observed for PCL/OS composites, which is related to the lowest content of proteins and lipids, moreover OS filler showed the highest content of lignin, which according to literature decomposes around $400{ }^{\circ} \mathrm{C}$ [37]. The peak $\mathrm{T}_{\max 1}$ on differential thermogravimetric curves is related to the degradation of applied fillers, e.g. their significant constituent-hemicellulose, which shows a decomposition stage in the range of $244-310{ }^{\circ} \mathrm{C}[22,37,63]$. Second peak, $\mathrm{T}_{\max 2}$ is related to the decomposition of PCL matrix. Its highest values were observed for composites containing $10 \mathrm{pbw}$ of fillers. This can be related to the reduced mobility of polymer matrix, what enhancing its thermal stability. These results are in line with the results of DMA analysis, e.g. constrained chains' volume. Nevertheless, the most important insight from TGA analysis is that thermal stability of composites containing $50 \mathrm{pbw}$ significantly exceeds $180{ }^{\circ} \mathrm{C}$. This is very important from technological point of view, because most of polyolefin-based WPC are processed near to this temperature. In Table 4 the values of weight residue of investigated biocomposites at $590{ }^{\circ} \mathrm{C}\left(\mathrm{wtr}^{590}\right)$ are also shown. The highest values of residue were noted for PCL/ WB composites, which can be related to the highest ash content of this filler (see Table 2). 
Table 4 Results of thermogravimetric analysis carried out for prepared biocomposites

\begin{tabular}{|c|c|c|c|c|c|c|c|}
\hline \multirow[t]{3}{*}{ Sample } & \multicolumn{4}{|c|}{ Mass loss, wt $\%$} & \multirow[t]{3}{*}{$\mathrm{T}_{\max 1},{ }^{\circ} \mathrm{C}$} & \multirow[t]{3}{*}{$\mathrm{T}_{\max 2},{ }^{\circ} \mathrm{C}$} & \multirow[t]{3}{*}{ wtr ${ }^{590}, w t \%$} \\
\hline & 2 & 5 & 10 & 50 & & & \\
\hline & \multicolumn{4}{|c|}{ Temperature, ${ }^{\circ} \mathrm{C}$} & & & \\
\hline PCL & 377.0 & 386.8 & 395.2 & 418.4 & - & 414.5 & 0.5 \\
\hline $\mathrm{PCL} \mathrm{OS}_{10}$ & 315.5 & 370.1 & 388.5 & 417.5 & 309.5 & 420.2 & 2.6 \\
\hline $\mathrm{PCL} \mathrm{OS}_{50}$ & 266.5 & 295.4 & 329.8 & 410.5 & 303.3 & 416.0 & 8.3 \\
\hline $\mathrm{PCL} / \mathrm{WB}_{10}$ & 289.7 & 336.1 & 384.7 & 416.7 & 309.8 & 420.5 & 4.0 \\
\hline $\mathrm{PCL} / \mathrm{WB}_{50}$ & 184.6 & 266.3 & 294.4 & 409.2 & 304.5 & 415.1 & 10.4 \\
\hline PCL/DS 10 & 301.5 & 344.4 & 386.9 & 417.2 & 307.4 & 421.4 & 1.4 \\
\hline $\mathrm{PCL} \mathrm{DS}_{50}$ & 262.4 & 289.5 & 303.7 & 414.9 & 306.0 & 419.3 & 7.3 \\
\hline
\end{tabular}

\section{Conclusions}

This manuscript presents the possibility of incorporation of OS, WB and DS into polymer biocomposites during manufacturing. PCL/OS and PCL/DS composites showed properties similar or even superior to those containing $\mathrm{WB}$, which has been already examined as a filler for WPCs based on biodegradable polymer matrix. Differences between composites containing WB and other fillers were related to the more than two times higher content of proteins in $\mathrm{WB}$, causing plasticization of polymer matrix. Such phenomenon noticeably affected mechanical properties of analyzed biocomposites, such as tensile strengtheven $34 \%$ increase. It was strongly associated with the higher content of polymer chains immobilized by OS and DS particles (over 7 and $28 \%$ increase), as determined by dynamic mechanical analysis, which was also related to the particle size of applied fillers. Composites containing WB were characterized by over $50 \%$ higher water uptake comparing to PCL/OS and PCL/DS materials. These dependences can be used in the future to design materials characterized by a desired water uptake, which strongly affects the course and rate of biocomposites' degradation. Presented results indicate that prepared OS, DS or WB filled biocomposites could be applied in many industrial applications.

Open Access This article is distributed under the terms of the Creative Commons Attribution 4.0 International License (http://creativeco mmons.org/licenses/by/4.0/), which permits unrestricted use, distribution, and reproduction in any medium, provided you give appropriate credit to the original author(s) and the source, provide a link to the Creative Commons license, and indicate if changes were made.

\section{References}

1. Faruk, O., Błędzki, A.K., Fink, H., Sain, M.: Progress in polymer science biocomposites reinforced with natural fibers: 2000-2010. Prog. Polym. Sci. 37, 1552-1596 (2012)

2. statista.com: New York: The Statistics Portal. https://www.statista. com/statistics/613466/olive-oil-production-volume-worldwide/ (2017). Accessed 07 Nov 2017

3. Parenti, A., Masella, P., Guerrini, L., Guiso, A., Spugnoli, P.: Energetic and economic viability of olive stone recovery as a renewable energy source: a Southern Italy case study. J. Agric. Eng. 45, 60-63 (2014)

4. Awad, A., Salman, H., Hung, Y.T.: Olive oil waste treatment. In: Yapijakis, C., Hung, Y.T., Lo, H.H., Wang, L.K. (eds.) Waste Treatment in the Food Processing Industry. CRC Press, Boca Raton (2005)

5. Rodriguez, G., Lama, A., Rodrigues, R., Jimenez, A., Guillen, R., Fernandez-Bolanos, J.: Olive stone an attractive source of bioactive and valuable compounds. Bioresour. Technol. 99, 5261-5269 (2008)

6. Cristofaro, D.: A process for the realization of plates and panels consisting of exhausted olive husks of crushed olive stones and polypropylene, and derived product. Patent WO 9738834 (1997)

7. Mousa, A., Heinrich, G., Wagenknecht, U.: Thermoplastic composites based on renewable natural resources: Unplasticized PVC/ olive husk. Int. J. Polym. Mater. 59, 843-853 (2010)

8. Siracusa, G., La Rosa, A.D., Siracusa, V., Trovato, M.: Eco-compatible use of olive husk as filler in thermoplastic composites. J. Polym. Environ. 9, 157-161 (2001)

9. Diab, K.A., Aboul-Ela, E.I.: In vivo comparative studies on antigenotoxicity of date palm (Phoenix dactylifera $\mathrm{L}$.) pits extract against DNA damage induced by $\mathrm{N}$-nitroso-N-methylurea in Mice. Toxicol. Int. 19, 279-286 (2012)

10. Demirbas, A.: Utilization of date biomass waste and date seed as bio-fuels source. Energy. Source A 39, 754-760 (2017)

11. Besbes, S., Ghorbel, R., Ben Salah, R., Masmoudi, M., Jedidi, F., Attia, H., Blecker, C.: Date fiber concentrate: chemical compositions, functional properties and effect on quality characteristics of beef burgers. J. Food Drug Anal. 18, 8-14 (2010)

12. Ambigaipalan, P., Shahidi, F.: Date seed flour and hydrolysates affect physicochemical properties of muffin. Food Biosci. 12, 54-60 (2015)

13. Baliga, M.S., Baliga, B.R.V., Kandathil, S.M., Bhat, H.P., Vayalil, P.K.: A review of the chemistry and pharmacology of the date fruits (Phoenix dactylifera L.). Food Res. Int. 44, 1812-1822 (2011) 
14. Ibrahim, H., Farag, M., Megahed, H., Mehanny, S.: Characteristics of starch-based biodegradable composites reinforced with date palm and flax fibers. Carbohydr. Polym. 101, 11-19 (2014)

15. Mahmoudi, N.: Use of date palm fibers as reinforcement for thermoplastic-based composites. Mech. Ind. 14, 71-77 (2013)

16. Mahmoudi, N., Hebbar, N.J.: Study of mechanical properties of a composite-based plant fibre of the palm and thermoplastic matrices (PP). J. Compos. Mater. 48, 291-299 (2014)

17. Shalwan, A., Yousif, B.F.: Investigation on interfacial adhesion of date palm/epoxy using fragmentation technique. Mater. Des. 53, 928-937 (2014)

18. Alsewailem, F.D., Binkhder, Y.A.: Preparation and characterization of polymer/date pits composites. J. Reinf. Plast. Compos. 29, 1743-1749 (2010)

19. Ghazanfari, A., Emami, S., Panigrahi, S., Tabil, L.G.: Themal and mechanical properties of blends and composites from HDPE and date pits particles. J. Compos. Mater. 42, 77-89 (2008)

20. AlMaadeed, M.A., Kahraman, R., Khanam, P.N., Madi, N.: Date palm wood flour/glass fibre reinforced hybrid composites of recycled polypropylene: mechanical and thermal properties. Mater. Des. 42, 289-294 (2012)

21. Mittal, V., Luckachan, G.E., Chernev, B., Matsko, N.B.: Bio-polyester-date seed powder composites: morphology and component migration. Polym. Eng. Sci. 55, 877-888 (2015)

22. Mittal, V., Chaudhry, A.U., Matsko, N.B.: "True" biocomposites with biopolyesters and date seed powder: mechanical, thermal, and degradation properties. J. Appl. Polym. Sci. 131, 40816 (2014)

23. Formela, K., Hejna, A., Zedler, Ł, Przybysz, M., Ryl, J., Saeb, M.R., Piszczyk, Ł: Structural, thermal and physico-mechanical properties of polyurethane/brewers' spent grain composite foams modified with ground tire rubber. Ind. Crops Prod. 108, 844-852 (2017)

24. Hejna, A., Haponiuk, J., Piszczyk, Ł, Klein, M., Formela, K.: Performance properties of rigid polyurethane-polyisocyanurate/ brewers' spent grain foamed composites as a function of isocyanate index. e-Polymers 17, 427-434 (2017)

25. Hejna, A., Formela, K., Saeb, M.R.: Processing, mechanical and thermal behavior assessments of polycaprolactone/agricultural wastes biocomposites. Ind. Crops Prod. 76, 725-733 (2015)

26. Formela, K., Hejna, A., Piszczyk, Ł, Saeb, M.R., Colom, X.: Processing and structure-property relationships of natural rubber/wheat bran biocomposites. Cellulose 23, 3157-3175 (2016)

27. Brostow, W., Lobland, H.E.H., Narkis, M.: Sliding wear, viscoelasticity, and brittleness of polymers. J. Mater. Res. 21, 2422-2428 (2006)

28. Chen, H.: Chemical composition and structure of natural lignocellulose. In: Chen, H. (ed.) Biotechnology of Lignocellulose. Dordrecht, Springer (2014)

29. Mainka, H., Täger, O., Körner, E., Liane, H., Sabine, B., Edelmann, F.T., Herrmann, A.S.: Lignin-an alternative precursor for sustainable and cost-effective automotive carbon fiber. J. Mater. Res. Technol. 4, 283-296 (2015)

30. Biesiekierski, J.R.: What is gluten? J. Gastroenterol. Hepatol. 32, 78-81 (2017)

31. González, J.F., González-García, C.M., Ramiro, A., González, J., Sabio, E., Gañán, J., Rodríguez, M.A.: Combustion optimisation of biomass residue pellets for domestic heating with a mural boiler. Biomass Bioenergy 27, 145-154 (2003)

32. Miranda, T., Esteban, A., Rojas, S., Montero, I., Ruiz, A.: Combustion analysis of different olive residues. Int. J. Mol. Sci. 9, 512-525 (2008)

33. Heredia, A., Guillén, R., Fernández-Bolaños, J., Rivas, M.: Olives stone as a source of fermentable sugars. Biomass 14, 143-148 (1987)
34. Caprez, A., Arrigoni, E.V.A., Amado, R., Neukom, H.: Influence of different types of thermal treatment on the chemical composition and physical properties of wheat bran. J. Cereal Sci. 4, 233-239 (1986)

35. Fraser, J.R., Holmes, D.C.: Proximate analysis of wheat flour carbohydrates. IV.-Analysis of wholemeal flour and some of its fractions. J. Sci. Food Agric. 10, 506-512 (1959)

36. Nabili, A., Fattoum, A., Passas, R., Elaloui, E.: Extraction and characterization of cellulose from date palm seeds (Phoenix dactylifera L.). Cellul. Chem. Technol. 50, 1015-1023 (2016)

37. Sisti, L., Totaro, G., Vannini, M., Fabbri, P., Kalia, S., Zatta, A., Celli, A.: Evaluation of the retting process as a pre-treatment of vegetable fibers for the preparation of high-performance polymer biocomposites. Ind. Crops Prod. 81, 56-65 (2016)

38. Yona, A.M.C., Budija, F., Kricej, B., Kutnara, A., Pavlic, M., Pori, P., Tavzes, C., Petric, M.: Production of biomaterials from cork: liquefaction in polyhydric alcohols at moderate temperatures. Ind. Crops Prod. 54, 296-301 (2014)

39. Kubo, S., Kadla, J.F.: Hydrogen bonding in lignin: a Fourier transform infrared model compound study. Biomacromolecules 6, 2815-2821 (2005)

40. Saccani, A., Sisti, L., Manzi, S., Fiorini, M.: PLC composites formulated recycling residuals of the winery industry. Polym. Compos. (2018) https://doi.org/10.1002/pc.24870

41. Schwanninger, M., Rodrigues, J.C., Pereira, H., Hinterstoisser, B.: Effects of short-time vibratory ball milling on the shape of FT-IR spectra of wood and cellulose. Vib. Spectrosc. 36, 23-40 (2004)

42. Das, K., Ray, D., Bandyopadhyay, N.R., Sengupta, S.: Study of the properties of microcrystalline cellulose particles from different renewable resources by XRD, FTIR, nanoindentation, TGA and SEM. J. Polym. Environ. 18, 355-363 (2010)

43. Sills, D.L., Gossett, J.M.: Using FTIR to predict saccharification from enzymatic hydrolysis of alkali pretreated biomasses. Biotechnol. Bioeng. 109, 353-362 (2012)

44. Verma, D., Katti, K., Katti, D.: Experimental investigation of interfaces in hydroxyapatite/polyacrylic acid/polycaprolactone composites using photoacoustic FTIR spectroscopy. J. Biomed. Mater. Res. 77, 59-66 (2006)

45. Svab, I., Musil, V., Pustak, A., Smit, I.: Wollastonite-reinforced polypropylene composites modified with novel metallocene EPR copolymers. I. Phase structure and morphology. Polym. Compos. 30, 1007-1015 (2009)

46. Elzein, T., Nasser-Eddine, M., Delaite, C., Bistac, S., Dumas, P.: FTIR study of polycaprolactone chain organization at interfaces. J. Colloid Interface Sci. 273, 381-387 (2004)

47. Kumari, R., Ito, H., Takatani, M., Uchiyama, M., Okamoto, T.: Fundamental studies on wood/cellulose-plastic composites: effects of composition and cellulose dimension on the properties of cellulose/PP composite. J. Wood Sci. 53, 470-480 (2007)

48. Khan, S.A., Prud'homme, R.K.: Melt rheology of filled thermoplastics. Rev. Chem. Eng. 4, 205-270 (1987)

49. Selmin, F., Franceschini, I., Cupone, I.E., Minghetti, P., Cilurzo, F.: Aminoacids as non-traditional plasticizers of maltodextrins fast-dissolving film. Carbohydr. Polym. 115, 613-616 (2015)

50. Formela, K., Hejna, A., Haponiuk, J., Tercjak, A.: In situ processing of biocomposites via reactive extrusion. In: Ray, D. (ed.) Biocomposites for High-Performance Applications. Current Barriers and Future Needs Towards Industrial Development. Woodhead Publishing, Duxford (2017)

51. Khan, R.A., Beck, S., Dussault, D., Salmieri, S., Bouchard, J., Lacroix, M.: Mechanical and barrier properties of nanocrystalline cellulose reinforced poly(caprolactone) composites: effect of gamma radiation. J. Appl. Polym. Sci. 129, 3038-3046 (2013)

52. Stein, T.M., Gordon, S.H., Greene, R.V.: Amino acids as plasticizers: II. Use of quantitative structure-property relationships to 
predict the behavior of monoammoniummonocarboxylate plasticizers in starch-glycerol blends. Carbohydr. Polym. 39, 7-16 (1999)

53. Barczewski, M., Matykiewicz, D., Piasecki, A., Szostak, M.: Polyethylene green composites modified with post agricultural waste filler: thermo-mechanical and damping properties. Compos. Interfaces 25, 287-299 (2018)

54. Sormana, J.L., Meredith, J.C.: High-throughput discovery of structure-mechanical property relationships for segmented poly(urethane-urea)s. Macromolecules 37, 2186-2195 (2004)

55. Correa, C.A., Razzino, C.A., Hage, E.: Role of maleated coupling agents on the interface adhesion of polypropylene-wood composites. J. Thermoplast. Compos. 20, 323-329 (2007)

56. Brostow, W., Lobland, H.E.H.: Brittleness of materials: implications for composites and a relation to impact strength. J. Mater. Sci. 45, 242-250 (2010)

57. Djidjelli, H., Boukerrou, A., Rabouhi, A., Founas, R., Kaci, M., Zefouni, O., Djillali, N., Belmouhoub, L.: Effect of olive residue benzylation on the thermal and mechanical properties of poly(vinyl chloride)/olive residue composites. J. Appl. Polym. Sci. 107, 1459-1465 (2008)
58. Barczewski, M., Mysiukiewicz, O., Klozinski, A.: Complex modification effect of linseed cake as an agricultural waste filler used in high density polyethylene composites. Iran. Polym. J. 27, 677-688 (2018)

59. Kaci, M., Djidjelli, H., Boukerrou, A., Zaidi, L.: Effect of wood filler treatment and EBAGMA compatibilizer on morphology and mechanical properties of low density polyethylene/olive husk flour composites. Express Polym. Lett. 1, 467-473 (2007)

60. Pickering, K.L., Efendy, M.A., Le, T.M.: A review of recent developments in natural fibre composites and their mechanical performance. Compos. A 83, 98-112 (2016)

61. Briffaz, A., Mestres, C., Matencio, F., Pons, B., Dornier, M.: Modelling starch phase transitions and water uptake of rice kernels during cooking. J. Cereal Sci. 58, 387-392 (2013)

62. Ma, W., Sutherland, M.W., Kammholz, S., Banks, P., Brennan, P., Bovill, W., Daggard, G.: Wheat flour protein content and water absorption analysis in a doubled haploid population. J. Cereal Sci. 45, 302-308 (2007)

63. Brebu, M., Vasile, C.: Thermal degradation of lignin-a review. Cellul. Chem. Technol. 44, 353-363 (2010) 